\title{
RUMINATIONS ON MUSIC AS AN EXEMPLARY ART
}

\author{
Arnold Berleant* \\ Long Island University
}

In a lifetime spent with music, listening and playing, I have always been struck by the remarkable self-sufficiency of that art. Faltering explanations, such as language, symbol, emotion, or expression, seem to reflect the preconceptions of the listener, the critic, or the theorist rather than the experience of the music. All claim to explain music in terms of something else. Where is the music in such explanations? Music loses its integrity through translation into similes, metaphors, or its accompanying effects. How, then, can we explain the fascination that music continues to exert on us?

\section{Titles}

As with other arts, music does occasionally exhibit referential features, and these are often put in titles or descriptive phrases. Can titles avoid the pitfall of translation? They seem to speak directly of the imitative characteristics that music may exhibit: of its mood, of non-musical sounds like cock's crowing and locomotives, or of dramatic events. Titles seem to offer a means of bringing order to the intangibilities of musical sound.

Yet titles are misleading in their own ways. We tend to seize on titles as hooks on which to hang our explanations, easily overlooking the wall on which

* Author contact information: aberleant@roadrunner.com 
they are fixed. How, we think, does the music embody the night on Bald Mountain or the sea? Sound recedes before image, drama, or feeling. We find ourselves listening anxiously for the cock's crowing in The Sorcerer's Apprentice or to recognize the march to the scaffold and the fall of the guillotine in the Symphonie fantastique. Again, what was to be an explanation tends to becomes a substitute for the musical work. There are numerous instances where, from titles assigned by the composer or the listener, the autonomy of music seems to be compromised. How to deal not only with so-called program music but with musical works that have descriptive titles, such as the overly-specific Moonlight Sonata? If music is about itself, what of those works whose titles make suggestive, external connections between the music and something else, notably the wonderfully evocative titles Debussy gave his Preludes?

Several plausible explanations are possible. The title could reflect the piece's generative source: the object, situation, or mood that evoked the composer's musical response, common in Impressionism. Or the title could act as a guide for the listener in making associations or suggesting an appropriate mood that could serve as a focal point for attention. Such accounts may not lead us far from the progression of musical sounds, but they cannot avoid dissipating our attention.

But we are still left with a question: is this connection a more or less explicit reference that is comparable to the images in representational painting or the characters and situation in a realistic novel? On the other hand, is the title nothing more than a largely arbitrary linguistic stipulation by the composer or someone else? Should the listener emulate Debussy's practice and consider the title only after listening to the work? Or to suggest a third alternative, is the object, person, situation, or mood something that is wholly embodied in the work of musical art? I should like to affirm the last of these. ${ }^{1}$

\section{A wordless sense of things}

One of the most persistent similes for explaining the elusive art of music is language. Likening music to language seems almost undebatable and, to be sure, there are certain apparent similarities. Both are sensuous social media shaped into syntactical-appearing structures. Both incorporate resonances of significance, although here it is not only the analogy, music with language, that is troublesome but the very manner in which meaning presumably occurs in each case. Much of the modern age of philosophy has, from the seventeenth

1 I have argued for this last alternative at greater length in "What Titles Don't Tell," Aesthetics beyond the Arts; New and Recent Essays (Farnham, UK \& Burlington, VT: Ashgate, 2012), Ch. 2. 
century on, been preoccupied with exactly how language embodies meaning and expresses truth, and the quest for an answer seems even more complex and unattainable now than it did three centuries ago. ${ }^{2}$ And in the case of music, questions of meaning, representation, and truth remain puzzlingly inchoate, even though the goal of attaining meaning, of explaining what music means, may seem as necessary as ever to an understanding of that art.

A critical difference holds, however, between music and language. Except for proper nouns, language is highly abstract, and the explanation of the ontological status of abstract terms has long been a matter of contention. Are they shorthand for collections of particulars or do abstractions have some kind of inherent status of their own on the model of platonic forms? Yet unlike the necessary abstraction of language, music possesses unique particularity. It is easy enough to identify the aural modes in which music occurs, such as scales, harmonic and contrapuntal textures, and dynamic variations. Terms such as these lead directly to tonal conditions and are not as likely to carry one away from aurality, but they are hardly modes of meaning.

An inherent difficulty resides in the effort to determine musical meaning. 'Meaning' can signify a variety of different things, from literal cognition to metaphorical significance, and this contributes to making meaning inadequate and misleading in relation to music. In the case of cognition, one cannot evade the particularity of every musical sound and sound structure: there is no equivalence to a musical experience. This leads to the difficulties in explaining the relationship in combinatory art forms such as between music and text and between music and a dramatic situation. Metaphorical meaning is no better. It rests on associations that are primarily personal and thus provides no objectively transferable content. The equivocal is music's normal regime since as a 'language' it bears meaning only indirectly and suggests without signifying. ${ }^{3}$

Rather than 'meaning' here, a term of unavoidable cognitive associations, it might be preferable to speak of 'resonance,' a word that at least derives its metaphorical significance from a musical source. 'Meaning,' then, is inadequate and misdirected: there is no equivalence to a musical experience. ${ }^{4}$ What, then, is left of musical meaning?

2 See John Hospers, Meaning and Truth in the Arts (University of North Carolina Press, 1948).

3 See, re the paradoxical mutuality of 'being-in,' the miracle of reciprocal inherence, Vladimir Jankélévitch, Music and the Ineffable (Princeton \& Oxford: Princeton University Press, (1961) 2003).

${ }^{4}$ Further ramifications include how to explain the relationship between music and text, between music and a dramatic situation. These are external relationships and do not bear as directly on music as sound. 
Let us set aside such metaphorical explanations of music as language and having meaning and consider music in the light of its inherent characteristics, as a wordless sense of things. Literal, direct features of musical sound, the modes of its sonic materials, so to say, are well known: pitch, volume, timbre, texture, harmony, melody, rhythm, tempo, and dynamics (volume). Important as these are for musical analysis, they identify rather than explain the sonic features of music. ${ }^{5}$ It is possible to further note other, less literal but equally intrinsic traits of musical sound that are less particular, such as its multi-dimensional auditory presence that imparts both a temporal and a spatial aura to the sonic experience. Music also exhibits degrees of intensity and kinds of density. These general characteristics result from the skillful combination of musical materials, especially spatiality, texture, and tonal quality or timbre of patterns of sounds or groups of instruments. Related to intensity but different from it is force. Oddly, we might seem to be describing the quasi-physics of musical sound by referring to its space, time, and force. Critically important in these two kinds of characterizations of music beyond words is that both the specific sonic features and especially the last group of pervasive features must be understood to apply to music as heard, that is, to the musical situation, for it is essential in understanding music always to consider it in its situational context as played and heard.

\section{Motion}

There is yet another aesthetic element that music reveals, a dimension of experience often hidden in other arts and rarely noted even in musical ones. The trait of which I am speaking is motion.

In one sense, ascribing motion to music seems obvious. I want to suggest, however, that it is neither obvious nor simple, and that motion underlies nearly every other musical dimension and can be found working its arcane influence in other arts, as well.

Motion is inherent in musical experience. One is reminded of Hanslick's famous definition of music as "tonally moving forms." Motion seems, at first, to apply to performance, to the activation of a musical score, but I want to contend that only in the aurality of music does music truly exist. That is to say, without being heard what remains of music is nothing more than vibrations in

\footnotetext{
5 I have discussed these in a somewhat different context in "What Music Isn't and How To Teach It," Action, Criticism, and Theory for Music Education, 8/1 (April 2009), 54-65. http://act.maydaygroup.org/php/current.php. Reprinted in Arnold Berleant, Aesthetics beyond the Arts (Farnham, UK \& Burlington, VT: Ashgate, 2012).

6 Eduard Hanslick, On the Musically Beautiful (1891), trans. G. Payzant (Indianapolis: Hackett, 1986).
} 
the air, just as an unseen painting is no more than pigment on canvas. Appreciative engagement is necessary for the art to exist. For music, this may occur in performances, but it may take place in listening to recordings. The musical score, like the title of a composition, is actually a path to sound, not the sound itself.

It is important here to distinguish between motion and movement. Movement is readily recognized as one of the dimensions of musical material. It has to do with the division of time into regular groups of pulsation (meter), at varying speeds (tempo), duration (note values), and patterns (rhythm). We can speak here, too, of melodic movement, harmonic movement (in which cadences are an important framing device), textural movement, and perhaps of tempo, the general pace of movement, and the degree of suspense (unresolved or deceptive cadences, extent and pattern of unresolvedness). Some of these forms of movement involve playing with anticipation by misleading or otherwise frustrating our expectations in musical audition. ${ }^{7}$

However, it is possible to identify another sense of movement that is less formal: its dynamic, somatic character. I am thinking here of something more like force, the pressing impulse of movement, the somatic experience of time. This is what I want to call motion as distinct from movement. It is the processive feature of all experience. Indeed, music takes this dynamic quality of time, central in perceptual experience, and gives it shape. Like all temporal experience (in contrast with metric chronology), musical motion is elastic. It is replete with accelerandos, ritardandos, fermatas, cadences, and other variations of the musical pulse.

It might be said that music is centered on motion through the use of sound and silence. Music is thus a sonic process. This is no less true of the other arts: painting is a visual process, cinema a filmic process, art in general a perceptual process. Because motion is central in music more clearly and directly than in most other arts, music is exemplary as a focused perceptual process.

Thus, music lies in the amalgam of sound, performer, and listener, and its embodiment is situated in the conjunction of the ongoing sound, the execution, and the listening. This has important implications for the ontology of music, which has often veered far from this mark. ${ }^{8}$

$7 C f$. Leonard Meyer, Emotion and Meaning in Music (Chicago: U.C. Press, 1956) Music, The Arts and Ideas (Chicago: UC Press, 1967).

8 It would be appropriate at this point to develop a discussion of musical embodiment, but as I have already written on that subject, I shall pass over it here and turn finally to the ostensible subject of this essay. See my "Embodied Music," in Environment and the Arts; Perspectives on Art and Environment, ed. A. Berleant (Ashgate, 2002), pp. 143-155. Also 


\section{Music as exemplary}

"To live in the music is like walking on a woodland trail." ${ }^{\prime \prime}$ For music to $b e$, one must participate in the living sound. This is a contextual experience. It brings together the participation of composer, sound, performer(s), and listener in an experiential synthesis, together with all the situational conditions of atmosphere, location, acoustics, technology, sociality, historicity, and other such circumstantial factors. Understood in this way, music is actually a social environmental experience. Its occasions can be profound and sometimes transformative. Although much of what I have said about music applies to most genres of music, what I especially have in mind here are those occasions when music dominates as the center of experience and is not made into a peripheral accompaniment as a space or time filler, or is not employed as a commercial or social facilitator (or seducer). I am thinking of musical occurrences when the music is the center of focused attention, especially of art music broadly construed.

Despite Walter Pater's famous claim that "All art constantly aspires towards the condition of music," 10 music has seldom been understood in its own terms. ${ }^{11}$ Even more rarely has music served as a standard for understanding other arts and activities. The prototypical arts are painting and literature. These, joined to the model of language with its attendant concepts of symbol, syntax, and semantics, have commonly been taken as the basis for grasping artistic forms, structures, experiences, and significance in general. Yet I have tried to show how musical processes do not fit these convenient molds. Moreover, some of the distinctive traits and capacities of musical art, such as direct and immediate sensation, intrinsic sensibility, temporality, intangibility, and an almost complete dependence on the activity of performance, are often overlooked or suppressed. While these features are present in other arts, music offers them with a clarity and directness not often found elsewhere. Music thus provides its own standard and may serve to advantage as a heuristic model for explaining the other arts. Let me first review the distinctive features of musical experience and then consider how they may be adapted to other arts and the implications of doing this.

TKS, Tidskrift för kulturstudier, (Journal of Cultural Studies), 5 (2002), 7-22. Reprinted in Arnold Berleant, Aesthetics and Environment, Theme and Variations (Farnham, UK \& Burlington, VT: Ashgate, Publishing Ltd, 2005).

9 Anon.

10 Walter Pater, "The School of Giorgione," The Renaissance: Studies in Art and Poetry, 2nd ed. (1877) and subsequent editions.

11 Schopenhauer was a notable exception. 


\section{1. direct and immediate sensation}

Whatever else happens in music (and much else does), it is an experience of sound. Skillful listening requires the ability to listen attentively and directly to sounds themselves. This is not confined to momentary sensation, a serious misunderstanding of perceptual immediacy. One hears in a temporal aura, in the mnemonic shadow, so to say, of what has been heard and with a projected umbra of anticipation of what may follow. This varies in degree with the extent of the music's familiarity but it is always present in close listening. It is evident that the capacity to attend to the intrinsic sensibility of music has to be cultivated, for attention easily wanders and is an easy victim to distraction.

\section{2. temporality}

To call attention to music's temporality is to state the obvious, and I have already mentioned the critical role of memory in the temporal experience of music. But temporality is not just an abstract property of music; it is a qualitative experience. Music is not only in time but it constitutes time. To live in time is to participate in a process, and the processive character of music is overt and distinctive. While this seems obvious, I say it because, as we shall see, every art involves a processive experience.

\section{3. intangibility}

This is worth mentioning although it, too, seems obvious. Unlike other, more "material" arts such as painting, sculpture, and architecture, the material of music, sound, is elusive. It can be "grasped" only in passing because it has no tangible substance. In this respect, music is closer to dance, whose "substance" is movement, not human bodies. Lights can dance and so can falling leaves, as well as elephants and horses (e.g. the Lipizzaner stallions).

\section{4. performance}

For music to happen, it requires the overt activity of performance. The composer, in a sense, is the first performer. The composer fashions the presence and succession of sounds, whether by playing an instrument, notating a score, or programming an electronic instrument. When music is re-performed, which is the status of concert performance, the process goes on before an audience through an intermediary. Performance is the actuality of music; everything else is contributory and peripheral. That is why it is impossible to locate a musical object as one can identify a presumed pictorial or visual one. Such an intention is vastly misleading because it thinks to locate the art in an object, whereas the art is actually in the experience to which the object contributes.

It is needless but necessary to note that these features are not separate and independent. Rather, they have been extrapolated from integral musical experi- 
ence only for the purpose of identifying and articulating its characteristics. Nor are these features unique to musical experience. They are present in other art modalities, too. Painting, for example, is a processive and performance art, not only for the artist in making (i.e. performing) the painting but for the viewer, as well, in actively examining and engaging with the features and qualities of the pictorial surface. Appreciation thus becomes a performance activity, and not only in music but in the aesthetic appreciation of poetry, fiction, dance, and architecture. One can discover other characteristics of musical experience in these arts, too, such as intrinsic sensation and temporality. Even intangibility is present, since the arts, in the sense in which I have been speaking of them, do not consist in objects such as canvases, sculptures, or buildings but in our aesthetic experiences of them. These arts, too, become complex modes of perceptual experience.

Carrying over these distinctive features of musical experience to other arts and examining how they function, mutatis mutandis, is revelatory as well as instructive. Considering music as exemplary transforms the aesthetics of the arts. 